\title{
The Fight for the Elimination of Racial and Ethnic Health Disparities: Acknowledging the Work and Celebrating the Life of Mr. Louis Stokes
}

\author{
Vivian W. Pinn ${ }^{1}$ - Cato T. Laurencin ${ }^{1,2,3,4}$
}

Received: 8 September 2015 /Revised: 14 September 2015 / Accepted: 16 September 2015 /Published online: 28 September 2015

(C) W. Montague Cobb-NMA Health Institute 2015

\begin{abstract}
The elimination of health disparities based upon race and ethnicity is a long road. The Honorable Louis Stokes was an indefatigable champion of the underserved who worked to create a world where the vision of health equity would not be a catchphrase but a reality.
\end{abstract}

The elimination of health disparities based upon race and ethnicity is a long road. As we take that road, it is important to remember and celebrate those along the way who in many ways have fashioned the trail for us to follow. The Honorable Louis Stokes (February 23, 1925-August 18, 2015) was an indefatigable champion of the underserved who worked to create a world where the vision of health equity would not be a catchphrase but a reality.

Congressman Stokes served 15 terms in the US House of Representatives beginning in 1969. He was known and respected for continually taking a stand on biomedical and community efforts to improve the plight of the medically underserved and less fortunate. His was often the voice of reason

Cato T. Laurencin

laurencin@uchc.edu

1 The W. Montague Cobb/NMA Health Institute, Washington, DC, USA

2 Institute for Regenerative Engineering, University of Connecticut Health Center, Farmington, CT, USA

3 Raymond and Beverly Sackler Center for Biomedical, Biological, Physical and Engineering Sciences, The University of Connecticut, Farmington, CT, USA

4 Department of Orthopaedic Surgery, The University of Connecticut, Farmington, CT, USA and influence, which led to actions that have and will continue to benefit those who may be affected by health disparities. As the first Black congressman elected from the state of Ohio, he served as one of the chairmen of the House Intelligence Committee, was the founding chair of the Congressional Black Caucus (CBC), led the House Ethics Committee as its chair, and was the first Black to serve on the esteemed House Appropriations Committee. His attention to health issues led to his appointment as a member of the Pepper Commission on Comprehensive Health Care. In these roles, he actively gave voice - and action - to health, health equity, and most of all, the elimination of health disparities.

Louis Stokes was the founding chair of the CBC Health Braintrust. In that role, he assured that during every occasion of the Health Braintrust, issues of importance for the elimination of health disparities were addressed. He ensured that leaders from the National Medical Association (NMA), our sister organization, and other organizations dedicated to the health of minority populations, the National Institutes of Health offices related to biomedical research that could lessen disparities, and community and civic leaders from across the country were always prominently featured in productive and educational programmatic interactions with the men and women who attended. As Chair of the CBC Health Braintrust, his contributions were manifold. He was one of the first public officials to emphasize the importance of addressing the AIDS epidemic in America, head on. He worked to provide innovative delivery systems for underrepresented minority communities, while at the same time proposed ways to address the dearth of minority physicians in America.

Mr. Stokes was adamant in his insistence that Federal commitments were advanced to promote the elimination of health disparities. He was a vocal and insistent proponent that the National Institutes of Health (NIH) provide organizational 
priority to health disparities research, supporting both the implementation of the National Institute on Minority Health and Health Disparities as well as budgetary and programmatic support for the NIH Office of Research on Women's Health. His contributions in support of the full biomedical research enterprise were recognized by the dedication of a building, The Louis Stokes Laboratories, on the NIH campus in 2001.

His legacy has been recognized by many other educational and organizational groups for which he was honored during his life. In addition to the NIH building named for him, the Cuyahoga Metropolitan Housing Authority houses Stokes memorabilia in the Louis Stokes Museum; Howard University's medical library is named for him as is the Louis Stokes Annex of the Cleveland Public Library and the Louis Stokes Health Sciences Center at Case Western Reserve University, Cleveland Public Library's main building expansion; and the Cleveland area Veteran's hospital was renamed the Louis Stokes Cleveland Department of Veteran Affairs Medical Center. The National Science Foundation's large and very successful program dedicated to broadening participation in STEM is named after Louis Stokes. LSAMP describes the over 21-year-old Louis Stokes Alliances for Minority Participation. LSAMP has served over 200,000 students and is dedicated to creating opportunities for the success of students at the baccalaureate degree level. A recipient of over 25 honorary degrees from various universities, $\mathrm{Mr}$. Stokes was honored by Congress on July 8, 2003, with the Congressional Distinguished Service Award.

An army veteran who attended Western Reserve University and Cleveland-Marshall College of Law, Mr. Stokes' life was an exemplary and inspiring illustration of a rise from modest origins to the highest levels of national leadership in the US government. He was pivotal in the struggle for civil rights, equality, social, and economic justice throughout his career. But the admiration and respect for him are most rooted in his gentle but strong strength of conscious and action, as a resilient gentleman who utilized his position for the benefit of others and addressing societal inequities, while never forgetting his origins or his home communities.

While we at the W. Montague Cobb/NMA Health Institute mourn the loss of the Honorable Louis Stokes, we move forward with the inspiration and determination that his life exemplified and that his career instilled in us. We have lost a champion for the elimination of health disparities and civil rights, but we have gained a valuable and vital legacy for our future because of him, and that both invigorates and sustains us.

Acknowledgment This work was supported by a National Institutes of Health (NIH)/BUILD award to Dr. Cato Laurencin. 